\title{
Risk factors for, and prevention of, shoulder injuries in overhead sports: a systematic review with best- evidence synthesis
}

\author{
Martin Asker, ${ }^{1,2}$ Hannah L Brooke, ${ }^{3}$ Markus Waldén, ${ }^{4,5,6}$ Ulrika Tranaeus, ${ }^{1,7}$ \\ Fredrik Johansson, ${ }^{1,2}$ Eva Skillgate, ${ }^{1,2}$ Lena W Holm ${ }^{1,3}$
}

- Additional material is published online only. To view, please visit the journal online (http://dx.doi.org/10.1136/ bjsports-2017-098254).

${ }^{1}$ Musculoskeletal and Sports Injury Epidemiology Center, Institute of Environmental Medicine, Karolinska Institutet, Stockholm, Sweden

${ }^{2}$ NaprapathögskolanScandinavian College of Naprapathic Manual Medicine, Stockholm, Sweden

${ }^{3}$ Unit of Epidemiology, Institute of Environmental Medicine,

Karolinska Institutet, Stockholm, Sweden

${ }^{4}$ Division of Community Medicine, Department of Medical and Health Sciences, Linköping University, Linköping, Sweden

${ }^{5}$ Department of Orthopaedics, Hässleholm-Kristianstad-Ystad Hospitals, Hässleholm, Sweden ${ }^{6}$ Football Research Group, Linköping, Sweden ${ }^{7}$ Performance and Training Unit, The Swedish School of Sport and Health Sciences, GIH, Stockholm, Sweden

\section{Correspondence to}

Martin Asker, Musculoskeletal and Sports Injury Epidemiology Center, Institute of

Environmental Medicine, Karolinska Institutet, Stockholm 171 77, Sweden;

martin.asker@ki.se

MA and HLB contributed equally.

Accepted 8 March 2018 Published Online First 26 March 2018

Check for updates

To cite: Asker $\mathrm{M}$, Brooke HL, Waldén $\mathrm{M}$, et al. Br I Sports Med 2018:52:1312-1319.

\section{ABSTRACT}

Objective To assess the evidence for risk factors and prevention measures for shoulder injuries in overhead sports.

Design Systematic review with best-evidence synthesis. Data sources Medline (Ovid), PubMed (complementary search), Embase (Elsevier), Cochrane (Wiley),

SPORTDiscus (Ebsco) and Web of Science Core Collection (Thomson Reuters), from 1 January 1990 to 15 May 2017.

\section{Eligibility criteria for selecting}

studies Randomised controlled trials, cohort studies and case-control studies on risk factors or prevention measures for shoulder injuries in overhead sports. The eligible studies were quality assessed using the Scottish Intercollegiate Guidelines Network criteria.

Results Of 4778 studies identified, 38 were eligible for quality review and 17 met the quality criteria to be included in the evidence synthesis. One additional quality study presented a shoulder injury prevention programme. Most studies focused on baseball, lacrosse or volleyball $(n=13)$. The risk factors examined included participation level (competition vs training) $(n=10)$, sex $(n=4)$, biomechanics $(n=2)$ and external workload $(n=2)$. The evidence for all risk factors was limited or conflicting. The effect of the prevention programme within the subgroup of uninjured players at baseline was modest and possibly lacked statistical power.

Conclusions All investigated potential risk factors

for shoulder injury in overhead sports had limited evidence, and most were non-modifiable (eg, sex). There is also limited evidence for the effect of shoulder injury prevention measures in overhead sports.

PROSPERO trial registration

number CRD42015026850.

\section{INTRODUCTION}

Shoulder injuries and shoulder pain are substantial problems in overhead athletes, such as baseball and softball pitchers or handball, volleyball, cricket and tennis players. ${ }^{1-7}$ The incidence of shoulder injuries in overhead sports varies between $0.2 / 1000$ hours and 1.8/1000 hours. ${ }^{389}$ The average proportion of athletes reporting weekly moderate or severe reductions in training volume or in sports performance, or complete inability to participate in sport due to a shoulder problem is $5 \%$ in secondary school male and female volleyball players and $12 \%$ in senior elite male handball players . ${ }^{110} \mathrm{Up}$ to $36 \%$ of senior elite female handball players report shoulder pain in the early preseason. ${ }^{11}$
The burden of shoulder problems highlights the need for injury prevention strategies. Identifying risk factors and developing strategies to prevent injury, based on these risk factors, are key components for preventing injuries in sports. This reflects the second and third step in the 'sequence of prevention' and 'translating research into injury prevention practice' models. ${ }^{12} 13$

Risk factors for shoulder injuries might vary among different overhead sports, since athletes participating in contact sports may be at higher risk of traumatic shoulder injuries. ${ }^{14-17}$ A common feature of overhead sports is the repetitive use of the shoulder with the hand above the head. Consequently, mechanisms linked to non-traumatic shoulder injuries may therefore not differ considerably between overhead sports. However, there may be sex and age differences in shoulder injury, since this has been observed in several other anatomical sites and sports. ${ }^{8} 1819$ Biomechanical factors, such as shoulder mobility, coordination and impaired throwing technique, may also be risk factors for shoulder injuries in overhead sports. ${ }^{20-23}$

Risk factors for injury in baseball, cricket, lacrosse, volleyball and water polo have been the subject of previous systematic reviews. ${ }^{24-29}$ However, risk factors for shoulder injury have only been assessed in two of these systematic reviews (assessing injuries in water polo and volleyball) ${ }^{27} 28$ Cross-sectional studies and studies with very small sample sizes were included in these systematic reviews ${ }^{27} 28$ and this limits the ability for researchers to draw conclusions about causal effects or temporality. Studies with small sample sizes are at increased risk of type II error. There is no systematic review investigating the effect of programmes to prevent shoulder injuries in overhead sports. Therefore, the aim of our systematic review was to assess the evidence for risk factors for shoulder injuries and the effect of primary shoulder injury prevention measures in overhead sports.

\section{METHODS}

The conduct and reporting of this systematic review follows the Preferred Reporting Items for Systematic Reviews and Meta-analyses statement (PRISMA). ${ }^{30}$ The study protocol was prospectively registered (PROSPERO ID: CRD42015026850).

\section{Eligibility criteria}

Randomised controlled trials, cohort studies and case-control studies, published in English, German, 
Swedish, Norwegian or Danish from 1 January 1990 to 15 May 2017 were eligible for quality appraisal. Eligible studies must include at least 20 human participants, of any age and playing level. Studies evaluating injury prevention programmes must include at least 20 participants in each group. Studies where the outcome was not clearly stated, or where shoulder injury/ pain was pooled with other anatomical locations (eg, upper arm/ elbow injuries combined) were excluded.

\section{Definitions and outcome}

We defined an overhead sport as a sport in which an athlete, with the forearm/hand lifted above the head, repetitively propels a ball or shuttle against an opponent or a teammate. We identified the following sports that fitted this definition: badminton, baseball, cricket, handball, lacrosse, softball, tennis, volleyball and water polo.

The case definition (outcome) was shoulder injury or shoulder pain, as defined in each study. Studies were required to report risk ratios, ORs, incidence rate ratios or HRs as estimates of injury risk, or include relevant raw data from which such estimates could be calculated.

\section{Literature search strategy}

Potentially relevant papers were identified by searching the following six online databases: Medline (Ovid), PubMed (complementary search), Embase (Elsevier), Cochrane (Wiley), Web of Science Core Collection (Thomson Reuters) and SPORTDiscus (Ebsco). Searches were designed with the aid of two experienced librarians at the University Library, Karolinska Institutet, Stockholm, Sweden (see online supplementary material 1). The search included terms related to shoulder injury and pain, sports and measures of association and prevention. Records were downloaded to Endnote X4 (Thomson Reuters) and duplicates were removed. We reviewed the reference lists of all included studies, and six systematic reviews on related topics, ${ }^{24-29}$ to help ensure that all relevant studies were identified.

\section{Study selection}

Each abstract was independently screened by two authors, who met to discuss any discrepancies in their assessments and reach agreement. In the next step, the full text of each eligible study was obtained and re-evaluated against the criteria described above. If discrepancies could not be resolved, all seven authors met for discussion and reached a consensus.

\section{Risk of bias assessment/quality appraisal}

The risk of bias in each eligible study was independently evaluated by two assessors using modified versions of the Scottish Intercollegiate Guidelines Network (SIGN) checklists (http:// www.sign.ac.uk/) (see online supplementary material 2). Any discrepancies were resolved by consensus. The SIGN checklists comprise 15 items with response categories 'yes', 'no', 'cannot say' and 'not applicable'. According to the guidance, studies that did not state the main outcome measures, that based the main conclusions on secondary outcomes, or for which outcomes and criteria for measuring them were not clearly defined or that did not address the possibility of confounding should be excluded from the systematic review. Otherwise, the internal validity of each study was evaluated based on (1) the process of subject selection, (2) measurement of outcomes and exposures, (3) sources of potential confounding and(4) the appropriateness of statistical analyses. The overall assessment was based on how well the study minimised the risk of bias and a judgement of
Box 1 SIGN guidance for ratings of the overall methodological quality

\section{High quality (++)}

Majority of criteria met. Little or no risk of bias. Results unlikely to be changed by further research.

\section{Acceptable (+)}

Most criteria met. Some flaws in the study with an associated risk of bias, Conclusions may change in the light of further studies.

\section{Borderline (-)}

Crude effect estimates have been presented or have been calculated (thus no confounders have been considered), but the study is otherwise acceptably sound with respect to other possible biases.

\section{Unacceptable-reject (0)}

Either most criteria not met, or significant flaws relating to key aspects of study design. Conclusions likely to change in the light of further studies.

whether the study could provide evidence of an association or no association between the exposure and outcome. We prespecified that studies must have included at least 10 exposed cases to be included in the systematic review. This was an arbitrary way to reduce the risk of non-systematic bias.

We modified the checklists as follows:

1. We added an extra question in the statistical analysis section: '1.15 Statistical analysis otherwise appropriate for the research question?' This question was necessary to capture any occasions where statistical analysis may have impacted on the study quality such as an increased likelihood of type 1 error associated with multiple significance testing.

2. We removed the question 'Are the results of this study directly applicable to the patient group targeted in this guideline?', since we did not aim to produce a clinical guideline.

3. We added an extra response category to item 2.1 'How well was the study done to minimise the risk of bias or confounding?' instead of rejecting studies outright (as the SIGN guidance suggests). Studies where potential confounding factors were not taken into account and those where only crude effect estimates could be calculated from raw data could be classified as 'borderline' rather than 'unacceptable', providing that there were no other major sources of bias identified. After completing the SIGN checklists, we classified each study as high quality, acceptable, borderline or unacceptable (box 1).

Full-text articles that were underpowered for shoulder injuries (ie, $<10$ exposed cases), did not report appropriate statistics or were considered below borderline quality (ie, at high risk of bias), were not included in the evidence synthesis (see online supplementary material 2). We did not assess publication bias or small study effects due to heterogeneity in the type of sports and the potential risk factors examined in each study. It was difficult to examine selective reporting within studies since protocols were not available for most of the included studies.

\section{Data extraction}

MA and LWH each extracted half of the main results and HLB extracted data for the quality assessment separately. MA and 


\section{Box 2 Evidence criteria for the best-evidence synthesis}

1. Strong evidence: evidence provided by two or more highquality studies and by generally consistent findings across these studies ( $\geq 75 \%$ of the studies reported consistent findings).

2. Moderate evidence: evidence provided by one high-quality study and/or multiple studies of acceptable quality and by generally consistent findings ( $\geq 75 \%$ of the studies reported consistent findings).

3. Limited evidence: evidence provided by one study of acceptable quality and/or one or more studies of borderline quality.

4. Conflicting evidence: inconsistent findings in multiple studies ( $<75 \%$ of the studies reported consistent findings).

5. No evidence: no admissible studies were found.

LWH subsequently cross-checked all extracted data together. Items for data extraction were: first author, year of publication, type of sport, sex of participants in the study (ie, male, female or both males and females), setting of the study, number of participants (or group level indication of study size if number of participants was not reported), inclusion/exclusion criteria, main exposure/risk factor, definition of injury/outcome, effect estimate or injury frequencies to calculate effect estimates, main limitations/sources of bias.

\section{Summary measures and synthesis of results}

The principal summary measures were rate ratios, risk ratios and ORs reported in studies or calculated (using Stata V.14.2, StataCorp) based on raw data provide in the studies. Given the heterogeneity in the studies, we did not conduct a meta-analysis. Instead, we present a best-evidence synthesis to clarify the direction and strength of evidence for each potential risk factor within each sport. ${ }^{31}$ The strength of evidence for each potential risk factor within each sport was assessed using an adapted version of previously defined criteria, ${ }^{32-34}$ which accounted for our extra category of 'borderline' quality studies (box 2).

\section{RESULTS}

\section{Study selection}

After searching the databases electronically and with the addition of two studies identified by screening reference lists, ${ }^{17}{ }^{35}$ 4778 records were screened for inclusion based on title and abstract (figure 1). Overall, 4740 studies were excluded at

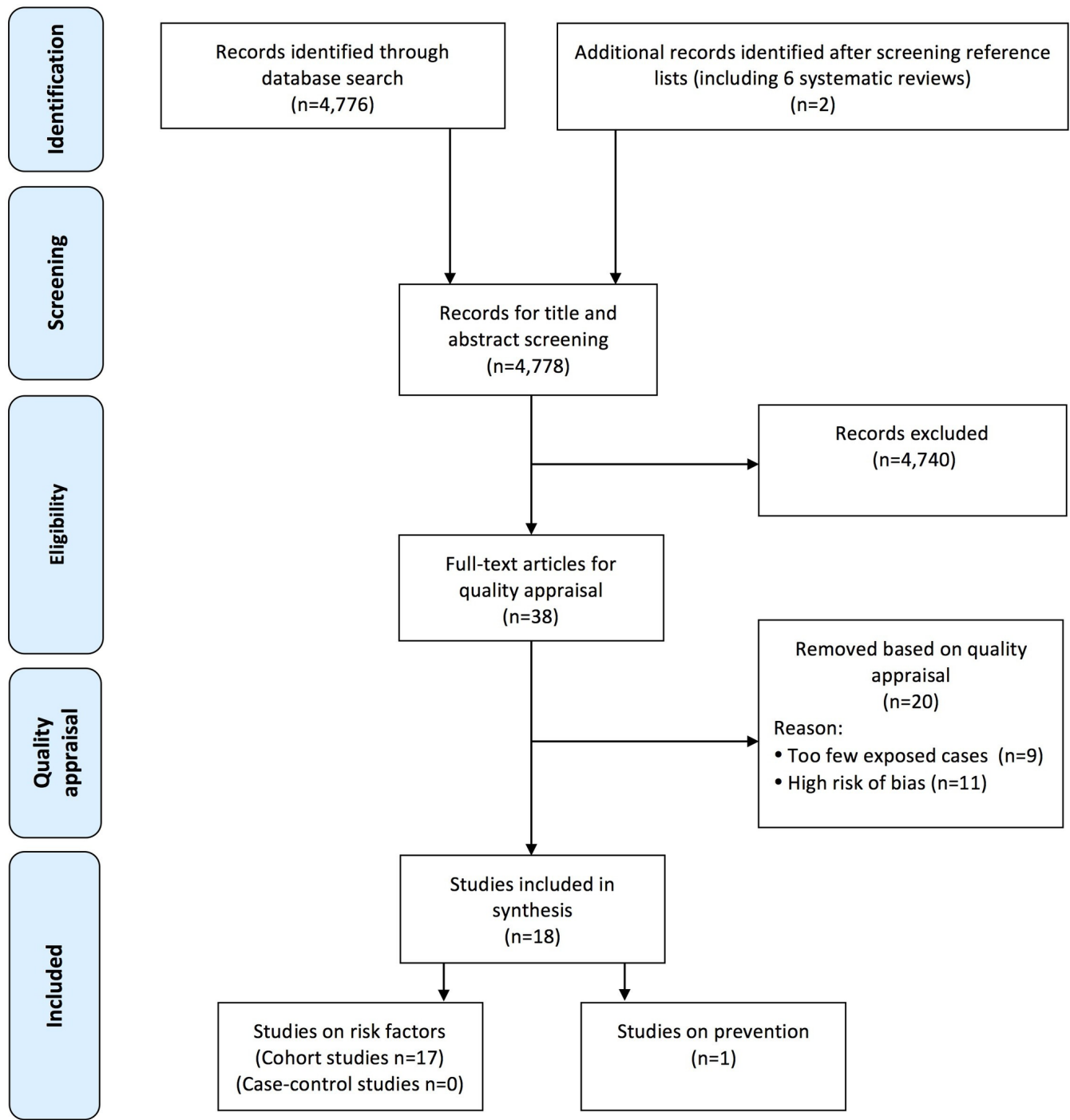

Figure 1 Flow diagram of literature search. 
this step. After quality appraisal of the remaining 38 studies, 17 studies were included in the best-evidence synthesis of risk factors for shoulder injuries. ${ }^{2}{ }^{15}{ }^{35-50}$ One study reported on a shoulder injury prevention programme. ${ }^{36}$ Nine studies could not contribute to the evidence due to high risk of non-systematic bias (low power) ${ }^{51-59}$ and were excluded from the best-evidence synthesis, as were 11 studies with high risk of systematic bias $^{71060-68}$ (see online supplementary material 3).

\section{Study characteristics}

Baseball was the most commonly studied overhead sport in the best-evidence synthesis (seven studies) and volleyball and lacrosse populations were evaluated in five studies. There were four studies that reported on softball players, three on handball players and one that included tennis and water polo players. Nine studies included collegiate athletes. ${ }^{15} 35383941-434648$ Six included youth/high school athletes ${ }^{374043444950}$ and three included elite/professional athletes. ${ }^{25} 47$

Ten studies compared the risk of shoulder injury between competition and training. Risk of shoulder injury was compared between males and females in four studies. ${ }^{2}{ }^{24} 48$ The modifiable risk factors examined were biomechanical measures, ${ }^{45} 47$ competition and training load, ${ }^{49} 50$ player position ${ }^{49}$ and history of shoulder or elbow pain. ${ }^{49}$ One study presented a prevention programme for shoulder injuries. ${ }^{36}$

\section{Risk of bias within studies}

The most frequent sources of potential bias were no or limited adjustment for potential confounders $(\mathrm{n}=15)$, and time at risk of shoulder injury measured at the group level $(n=10)$ (see online supplementary material 4,5 ).

\section{Synthesis of results}

The best-evidence synthesis is presented in table 1 and described briefly below. The characteristics of individual studies of risk factors included in the best-evidence synthesis are presented in online supplementary material 4 and the study on prevention is presented in online supplementary material 5 . The studies appraised as inadmissible for the best-evidence synthesis are briefly described in online supplementary material 6.

\section{Participation settings (competition vs training)}

Three studies examined non-specific shoulder injuries in competition versus training in high school students and there were conflicting evidence for all three sports. ${ }^{37444}$ There was limited evidence of an increased risk of non-traumatic shoulder injuries in competition compared with training in men's baseball. ${ }^{38}$ In women's softball and volleyball there was limited evidence of a decreased risk of non-traumatic shoulder injuries in competition compared with training. ${ }^{354}$

There was limited evidence of an increased risk of traumatic shoulder injuries in competition for men's baseball, women's volleyball and men's and women's lacrosse..$^{15} 353839414246$ There was limited evidence of no increased risk of traumatic shoulder injuries in competition versus training for women's softball. ${ }^{41}{ }^{42}$

\section{Sex}

Four studies compared shoulder injury risk between male and female athletes. ${ }^{2} 404248$ There was limited evidence for an increased risk of shoulder injuries in male high school and college lacrosse players compared with female players. ${ }^{40} 42$ There was limited evidence of no sex differences in shoulder injuries among elite handball players ${ }^{2}$ and college tennis players, ${ }^{48}$ and limited evidence of a decreased risk of shoulder injury among male college water polo players compared with female players. ${ }^{48}$

\section{Playing position}

There was limited evidence that pitchers and catchers had an increased risk of shoulder injuries compared with outfielders in youth baseball. ${ }^{49}$

\section{External load}

There was limited evidence that a high number of training hours per week ( $>16$ hours/week) was associated with a higher injury risk among youth baseball pitchers and catchers. ${ }^{49}$ There was limited evidence that a large increase in training and/or match load ( $>60 \%$ increase compared with the average of the previous 4 weeks) was associated with higher risk of injury in youth handball players. ${ }^{50}$

\section{History of injury}

There was limited evidence that junior baseball pitchers and catchers with a history of shoulder pain or elbow pain were at higher risk of injury than those without history of pain ${ }^{49}$ (see online supplementary material 4).

\section{Shoulder range of motion}

Among US baseball pitchers with glenohumeral internal rotation deficit, total rotation deficit or flexion deficit, there was limited evidence of no association between shoulder range of motion and being placed on the disabled list. There was limited evidence that players with insufficient external rotation ( $>5^{\circ}$ less than non-dominant shoulder) had higher odds of being placed on the disabled list compared with those without insufficient external rotation. ${ }^{45}$ There was limited evidence of an association between greater humeral torsion in the dominant arm of US baseball pitchers $\left(3.5^{\circ}\right.$ greater) and shoulder injury. ${ }^{47}$

\section{Prevention studies}

We identified one study on prevention of shoulder injuries in overhead sports. ${ }^{33}$ This study focused on Norwegian highlevel male and female handball players, and the intervention aimed to improve players' glenohumeral internal range of motion, external rotation strength, scapular muscle strength, thoracic mobility and improve the kinetic chain. The results specific to those without shoulder problems at the start of the study, indicate some benefits in preventing shoulder problems with a stronger effect reported for substantial shoulder problems; however, the precision of the effect estimate was low and the potential biases may have led to an overestimation or underestimation of the effect (see online supplementary material 5).

\section{DISCUSSION}

We included 17 studies that evaluated risk factors for shoulder injuries in overhead sports. The principal findings were that studies were of low quality, there was little consistency in the results and few risk factors have been explored in more than one study. Only one study on injury prevention was included. The evidence is as such limited and raises the question whether practitioners should examine shoulder parameters from a performance or return to play perspective, rather than an injury prevention perspective. 
Table 1 Best-evidence synthesis of risk factors for shoulder injury in overhead sports

\begin{tabular}{|c|c|c|c|c|c|}
\hline Risk factors & $\mathrm{N}, \mathrm{PS}$ or number of $\mathrm{AE}$ & Type of sports & $\begin{array}{l}\text { Acceptable/borderline } \\
\text { quality (reference) }\end{array}$ & $\begin{array}{l}\text { Association with risk } \\
\uparrow / \downarrow /=\text { (reference) }\end{array}$ & Best-evidence synthesis \\
\hline \multirow{3}{*}{$\begin{array}{l}\text { Participation setting } \\
\text { (competition vs training- } \\
\text { non-specific injuries*) }\end{array}$} & $A E=1545730$ & Boys' baseball & 3744 & $={ }^{37} \uparrow 3744$ & Conflicting \\
\hline & $A E=1401368$ & Girls' softball & 3744 & $={ }^{37} \uparrow 3744$ & Conflicting \\
\hline & $A E=1166382$ & $\begin{array}{l}\text { Girls' and women's } \\
\text { volleyball }\end{array}$ & 374344 & $={ }^{3743} \downarrow^{44}$ & Conflicting \\
\hline \multirow{3}{*}{$\begin{array}{l}\text { Participation setting } \\
\text { (competition vs training- } \\
\text { non-traumatic injuriest) }\end{array}$} & $\begin{array}{l}\mathrm{AE}=\text { approximately } 2800 \\
000\end{array}$ & Men's baseball & 38 & $\uparrow^{38}$ & Limited \\
\hline & $\begin{array}{l}\mathrm{AE}=\text { approximately } 1650 \\
000\end{array}$ & Women's softball & 41 & $\downarrow^{41}$ & Limited \\
\hline & $\begin{array}{l}\mathrm{AE}=\text { approximately } 1576 \\
500\end{array}$ & Women's volleyball & 35 & $\downarrow^{35}$ & Limited \\
\hline \multirow{4}{*}{$\begin{array}{l}\text { Participation setting } \\
\text { (competition vs training - } \\
\text { traumatic injuries } \ddagger \text { ) }\end{array}$} & $\begin{array}{l}\mathrm{AE}=\text { approximately } 5678 \\
028\end{array}$ & Men's baseball & 3842 & $\uparrow^{3842}$ & Limited \\
\hline & $\begin{array}{l}\mathrm{AE}=\text { approximately } 3294 \\
365\end{array}$ & Women's softball & 4142 & $={ }^{4142}$ & Limited \\
\hline & $\begin{array}{l}\text { AE=approximately } 3213 \\
533\end{array}$ & Women's volleyball & 3542 & $\uparrow^{3542}$ & Limited \\
\hline & $A E \geq 5781051$ and 6528 PS & $\begin{array}{l}\text { Men's and women's } \\
\text { lacrosse }\end{array}$ & 15394246 & $\uparrow^{15394246}$ & Limited \\
\hline \multirow[t]{3}{*}{$\begin{array}{l}\text { Sex (males vs females- } \\
\text { contact sports) }\end{array}$} & $\mathrm{AE}=1910078$ and $6528 \mathrm{PS}$ & $\begin{array}{l}\text { Men's and women's' } \\
\text { lacrosse, boys' and girls' } \\
\text { lacrosse }\end{array}$ & 4042 & $\uparrow^{4042}$ & Limited \\
\hline & $\mathrm{n}=336$ & $\begin{array}{l}\text { Men's and women's } \\
\text { handball }\end{array}$ & 2 & $={ }^{2}$ & Limited \\
\hline & $\mathrm{AE}=$ not reported & $\begin{array}{l}\text { Men's and women's water } \\
\text { polo }\end{array}$ & 48 & $\downarrow^{48}$ & Limited \\
\hline $\begin{array}{l}\text { Sex (males vs females- } \\
\text { non-contact sports) }\end{array}$ & $\mathrm{AE}=$ not reported & Men's and women's tennis & 48 & $={ }^{48}$ & Limited \\
\hline $\begin{array}{l}\text { Playing position (pitchers } \\
\text { and catchers vs outfielders) }\end{array}$ & $\mathrm{n}=1020$ & Youth baseball & 49 & $\uparrow^{49}$ & Limited \\
\hline $\begin{array}{l}\text { External workload (higher } \\
\text { number of training hours/ } \\
\text { week) }\end{array}$ & $n=1020$ & Youth baseball & 49 & $\uparrow^{49}$ & Limited \\
\hline History of shoulder pain & $n=1020$ & Youth baseball & 49 & $\uparrow^{49}$ & Limited \\
\hline History of elbow pain & $n=1020$ & Youth baseball & 49 & $\uparrow^{49}$ & Limited \\
\hline $\begin{array}{l}\text { External workload (large } \\
\text { increase in weekly training/ } \\
\text { match load) }\end{array}$ & $\mathrm{n}=679$ & Youth handball & 50 & $\uparrow^{50}$ & Limited \\
\hline Biomechanics (GIRD) & $P S=170$ & Men's baseball & 45 & $={ }^{45}$ & Limited \\
\hline $\begin{array}{l}\text { Biomechanics (total ROM } \\
\text { deficit) }\end{array}$ & $P S=170$ & Men's baseball & 45 & $={ }^{45}$ & Limited \\
\hline $\begin{array}{l}\text { Biomechanics (flexion } \\
\text { deficit) }\end{array}$ & $P S=170$ & Men's baseball & 45 & $={ }^{45}$ & Limited \\
\hline $\begin{array}{l}\text { Biomechanics (insufficient } \\
\text { external rotation) }\end{array}$ & $P S=170$ & Men's baseball & 45 & $\uparrow^{45}$ & Limited \\
\hline $\begin{array}{l}\text { Biomechanics (humeral } \\
\text { torsion) }\end{array}$ & $P S=255$ & Men's baseball & 47 & $\uparrow^{47}$ & Limited \\
\hline
\end{tabular}

No studies of high quality were identified. 1. Strong evidence: evidence provided by two or more high-quality studies and by generally consistent findings across these studies ( $\geq 75 \%$ of the studies reported consistent findings). 2 . Moderate evidence: evidence provided by one high-quality study and/or multiple studies of acceptable quality and by generally consistent findings ( $\geq 75 \%$ of the studies reported consistent findings). 3. Limited evidence: evidence provided by one study of acceptable quality and/or one or more studies of borderline quality. 4. Conflicting evidence: inconsistent findings in multiple studies ( $<75 \%$ of the studies reported consistent findings). 5 . No evidence: no admissible studies were found.

* Studies with no specific diagnosis reported.

†Tendinitis, overuse injuries.

¥Contusions, muscle tendon strains, shoulder subluxations, shoulder dislocations, ligament sprains, acromioclavicular joint sprains.

$\S$ No increased risk was seen for tendons strain.

$\uparrow$, Associated with increased risk; =, no association; $\downarrow$, associated with decreased risk; AE, athletic exposure; GIRD, glenohumeral internal rotation deficit; N, number; PS, player season; ROM, range of motion.

\section{The evidence for risk factors for shoulder injuries in overhead sports is limited}

We found limited evidence that male lacrosse players had a higher incidence of shoulder injuries compared with female players, both during competition and training. ${ }^{40} 42$ This could be due to male players experiencing higher impact during collisions. In contrast, there was limited evidence that female water polo players had a higher risk of shoulder injury than their 
male counterparts. ${ }^{48}$ There was also limited evidence of no sex differences in overuse injuries in handball. ${ }^{2}$ These findings on shoulder injuries in overhead sports, although varying between sports, are supported by several recent reviews that identified sex differences in the risk for concussions, ${ }^{69}$ groin injuries ${ }^{70}$ and ACL injuries. ${ }^{71}$

Factors such as competition versus training, and sex, are non-modifiable risk factors, also described as risk indicators. Such factors can be used to identify target populations for interventions aiming to prevent injuries. Investigating modifiable risk factors, such as biomechanical, physiological and psychological measures, alongside modifiable training factors, is required to develop successful measures to prevent injury. Four studies in this review evaluated modifiable risk factors. There was limited evidence that a lack of external rotation (but no other shoulder joint range of motion measures) may be a risk factor for shoulder injuries in baseball pitchers. ${ }^{45}$ This is in line with a recent cross-sectional study (which was not included in this review due to the study design), showing that pitchers with shoulder pain have reduced external and total rotation range of motion. ${ }^{20}$ There was limited evidence of greater humeral torsion among baseball players who developed a shoulder injury. ${ }^{47}$ Furthermore, there was limited evidence for an increased risk of shoulder injury when training and match load in youth handball players increased $>60 \%$ in the week before injury compared with the average load of the preceding 4 weeks, ${ }^{50}$ or if youth baseball players participated in a high volume of training each week. ${ }^{49}$ Since change in training load is under the control of coaches, and the athletes themselves to some extent, training load may be an effective target for interventions that aiming at shoulder injury prevention in overhead sports.

\section{The evidence for measures to prevent shoulder injuries in overhead sports is limited}

The risk for substantial shoulder problem was reduced among a subgroup of senior male and female handball players without shoulder problems at baseline, who were exposed to a comprehensive strength and conditioning intervention. ${ }^{36}$ This finding was the result of a subanalysis, so it has low statistical power. Even though these results indicate some success of the intervention at preventing shoulder problems, the effect estimate was imprecise and the potential biases may have led to an overestimate or underestimate of the effect. Nonetheless, lack of compliance to the intervention and more strength training among controls may have contributed to an underestimation of the overall results.

\section{Key methodological aspects}

There are eight key methodological aspects that might affect the strength of evidence in our systematic review, and the results must be interpreted in light of these considerations.

\section{Injury registration and definitions}

There was large variation in the definition and registration of shoulder injuries. Most studies used a time-loss definition (ie, injuries leading to restricted participation for at least 1 day or the player being placed on the disabled list). ${ }^{2} 153537-424449$ This definition underestimates the incidence of overuse injuries since many athletes continue playing despite substantial shoulder problems. ${ }^{10}$ However, such underestimation does not affect the risk estimates unless it differs between categories of the exposure. Other studies defined injury as a shoulder problem irrespective of the need for time loss or medical attention, ${ }^{50}$ or shoulder problems/pain that impaired participation or performance or required surgery. ${ }^{3645}$

\section{Time at risk of shoulder injury}

Most studies reported time at risk on a group level (ie, counting one competition or training session as an athlete-exposure). Although pragmatic, this denominator results in less precise estimates of the incidence rate, since each individual's time at risk is unknown. If players are more prone to injury at the beginning of a competition, the incidence rates will be overestimated. One of the studies excluded from the best-evidence synthesis compared the incidence of shoulder injuries between male and female tennis players, using match events instead of match time as the denominator ${ }^{67}$ despite men's matches being longer than women's matches at the US Open, thus time at risk differed between men and women and is likely to explain the increased risk observed in men.

\section{Distinguishing between traumatic and non-traumatic injuries}

Most studies did not distinguish between traumatic and non-traumatic injuries. Since the injury mechanism differs, risk factors for these two types of injuries may also differ, thus the results of these studies are less specific. However, for several studies comparing competition with training, traumatic or non-traumatic could be inferred by the type of diagnosis presented. In baseball, there was limited evidence of higher risk of both non-traumatic and traumatic shoulder injuries during competition than during training. ${ }^{38}$ There was limited evidence for a higher risk of traumatic shoulder injuries during volleyball competition. ${ }^{35}{ }^{42} \mathrm{In}$ women's softball, the evidence for traumatic injury in competition compared with training was conflicting, ${ }^{41} 42$ while there was limited evidence for a higher risk of non-traumatic injuries during training. ${ }^{41}$ In lacrosse, there was limited evidence for a higher risk of shoulder injuries during competition. ${ }^{15} 394246$

\section{Competition and training demands}

History of shoulder problems, years of playing experience and training load may be associated with both the chance of playing in a competition and the risk of injury, thus the associations may be distorted by confounding factors. However, the higher risk of injury during competition compared with training in overhead sports is in line with other non-overhead sports such as the football codes, most likely since the intensity of the game is higher during competition. ${ }^{37273}$ In contrast, players may repetitively perform a specific motion during training, for example, throwing, bowling or spiking, which may explain the higher number of typically non-traumatic injuries seen during training compared with competition in some studies. ${ }^{3541}$

\section{Absence of the outcome at baseline}

Many studies considered for inclusion in this review allowed both injured and non-injured athletes to be included in the study. Consequently, it was not possible to examine risk factors due to the high risk of reverse causality (ie, the outcome may have influenced the exposure). ${ }^{10} 52$ Excluding injured athletes at baseline is straightforward in most occasions. However, pragmatic definitions of overuse injuries are often based on perceived pain or impairment in performance or participation, compared with traumatic injuries where time-loss definitions are often used ${ }^{10} 74$ making it challenging to define a healthy cohort when studying risk factors for overuse injuries. 
History of injury and definition of re-injury and new injury Controlling for history of shoulder injuries and defining a pragmatic time window for a re-injury to be a new injury are important in studies of modifiable risk factors. ${ }^{75}$ In practice, some studies may have measured injury prevalence multiple times instead of measuring the incidence of new injuries. ${ }^{576162}$ The implication is that risk estimates may be distorted in any direction.

\section{Generalisability to youth athletes}

Only 6 of the 17 studies included individuals of high school age or younger. This is a problem for the practitioners because the risk factors and therefore the prevention strategies may differ between senior and youth athletes. Therefore, future research studying young populations are of utmost importance to understand potential modifiable risk factors, and to help identify the age at which prevention strategies should be implemented.

\section{Confounding}

Only two of the included studies controlled for potential confounding. ${ }^{45}{ }^{49}$ Stepwise selection algorithms should not be used to select confounders since they place an overemphasis on $\mathrm{P}$ values. ${ }^{76}$ Confounders must be measured and chosen a priori, based on known or potential risk factors for the outcome that may be unevenly distributed among exposed and unexposed individuals. Otherwise effect estimates are likely to be distorted (upwards or downwards) which might, in some instances, fully explain the results. However, most effect estimates in the included studies were relatively high, suggesting that confounding is unlikely to fully account for the associations between risk factors and injury.

\section{What should the practitioner do?}

As with many sports injuries, the evidence for risk factors and the effect of prevention measures on shoulder injuries in overhead sports is limited. Practitioners strive to build their work on scientific evidence, but in absence of evidence or if the evidence is limited they cannot ignore the athlete in front of them just because there is no evidence from systematic reviews, highquality prospective cohort studies or randomised controlled trials. ${ }^{77}$ Sackett et al stated 'The practice of evidence-based medicine means integrating individual clinical expertise with the best available external clinical evidence from systematic research' ${ }^{78}$ Therefore, we offer two practical suggestions:

1. The practice of screening shoulder parameters, for the purpose of deciding which athletes should receive prevention strategies, should be questioned. ${ }^{79}$ Since there is limited evidence for which potential risk factors to assess or what prevention strategy to employ, the main purpose of screening shoulder parameters in overhead sports should be to evaluate current shoulder status, measure improvements in performance or to serve as normative values to reach before return to play after injury. ${ }^{79-81}$

2. When the evidence is limited, as is evident in many areas of sports medicine, the second best option is to look for position statements and expert panel opinions. ${ }^{77}$ However, one must recognise that these are based on experience and prone to changes as new evidence is presented.

\section{Future research}

There are several methodological flaws in the literature on risk factors of shoulder injuries in overhead sports. It is important to address these issues in future studies. We therefore present
Box 3 Recommendations for future research in the field

- When planning the study, make a well-informed estimation of the likely number of cases during the follow-up period to avoid the risk of low statistical power in the analyses of potential associations, potential confounders and effect modifiers.

- Take potential confounding into consideration in the analyses of associations between the exposure and an outcome if the study is not a large randomised controlled trial. Confounders must be chosen a priori based on known or potential risk factors for the outcome that may be unevenly distributed among exposed and unexposed individuals.

- Stepwise selection algorithms should not be used to select confounders since they place an overemphasis on $\mathrm{P}$ values.

- In prevention studies, do address the effect on injury risk, and assess if the preventive measures have effect on the factors that were hypothesised to influence injury risk, for example, biomechanical or physiological measures.

- Differentiate between incidence and prevalence, and preferably use incidence rate or incidence proportion when examining risk factors for injury.

- Distinguish between traumatic and non-traumatic injuries, since these types of injuries potentially have different injury mechanisms and as such, different risk factors.

- Present a clear definition of a healthy cohort at baseline in risk analyses, to avoid the risk of reverse causality.

- Specify the time frame when it is reasonable that an injured player is considered to be at risk for a new injury (ie, subsequent injury categorisation).

- Measure time at risk on an individual basis, rather than on group level for a more precise estimate of the incidence rate.

- Present crude results as well as results adjusted for identified confounders with $\mathrm{Cls}$. This gives the reader a better understanding of the influence of the confounders and it improves understanding of what potential confounders should be included in baseline measures of future studies.

recommendations to take into account in future studies on risk factors for and prevention of shoulder injuries in overhead sports (box 3).

\section{Strengths and limitations}

The main strengths of this systematic review are the extensive search of all major databases in the field, the rigorous method of evaluating papers for inclusion and the approach to account for study quality and risk of bias in evaluation of the evidence.

There are also some shortcomings with our study. First, included studies were too diverse for meaningful quantitative analyses, for example, meta-analysis. Second, many of the studies relied on data from the same database, ${ }^{15} 35$ 37-39 41-44 and are subject to the same sources of bias. In addition, this wrongly inflates the quantity of evidence because, despite slight differences in the definition of shoulder injury, some papers have reported results based on the same data, for example, competition versus training in lacrosse for the same time period. ${ }^{35} 42$ Third, except for the studies of the US high school and college athletes, sample sizes were generally small with few new shoulder injuries. However, more than half of the included studies were not conducted with the aim to study risk factors, but rather to describe the incidence of shoulder injuries, stratified by the exposures. We therefore used the raw data from those studies to calculate the 
risk estimates and precision, thus by default only crude results could be presented. Finally, we reviewed the reference lists of all studies eligible for quality appraisal and six systematic reviews on related topics, to help ensure that all relevant studies were identified. However, we did not do any citation tracking of these studies and we did not search grey literature. Nonetheless, we think that the impact of publication bias is minimal since results published in grey literature are likely of lower quality and thus would most probably not change our conclusions.

\section{CONCLUSIONS}

All investigated potential risk factors for shoulder injury in overhead sports had limited evidence, and most were non-modifiable (eg, sex). There is also limited evidence for the effect of shoulder injury prevention measures in overhead sports.

\section{What are the new findings?}

- The evidence on potential risk factors for shoulder injury in overhead sports is limited as is the evidence on effect of prevention measures. Most studies investigate nonmodifiable risk factors and generally they are underpowered, do not control for confounding, do not have a clear definition of a healthy cohort and/or do not differentiate between prevalence and incidence of injury. There was a tendency of a primary preventive effect of a comprehensive strength and conditioning training programme on the risk of shoulder injury in symptom-free handball players, but further and larger studies are needed.

\section{How might it impact on clinical practice?}

- These findings raise the question whether practitioners should examine shoulder parameters from a performance or return to play perspective, rather than an injury prevention perspective. Due to the lack of high-quality studies and the fact that most of the risk factors investigated are non-modifiable, no evidence-based recommendations for prevention of new shoulder injury in overhead sports can currently be made.

Twitter Follow Martin Asker @martinasker, Hannah Brooke @H_L_Brooke, Markus Waldén @MarkusWalden, Ulrika Tranaeus @UlrikaTranaeus, Fredrik Johansson @ frjohansson, Eva Skillgate @skillgate_eva, Lena Holm @lw_holm.

Acknowledgements The authors would like to thank the librarians Klas Moberg and Gun Brit Knutsön at the University Library Karolinska Institutet, Sweden, for building the search strategy and performing the searches of the databases. Matilda Tryggvesson is also acknowledged for important help with the administrative part of the study.

Contributors MA, ES and LWH participated in the conception and design of the study. All authors were active in the screening procedure of studies retrieved in the literature search and in the procedure of assessing the quality of the relevant studies. MA, HLB and LWH extracted and analysed the data. MA and HLB drafted the manuscript and contributed equally (joint first authorship). All authors critically revised the manuscript for important intellectual content and approved the final version. LWH is the study guarantor.

Funding The authors have not declared a specific grant for this research from any funding agency in the public, commercial or not-for-profit sectors.

Competing interests None declared.

Patient consent Not required.

Provenance and peer review Not commissioned; externally peer reviewed.

(c) Article author(s) (or their employer(s) unless otherwise stated in the text of the article) 2018. All rights reserved. No commercial use is permitted unless otherwise expressly granted.

\section{REFERENCES}

1 Clarsen B, Bahr R, Heymans MW, et al. The prevalence and impact of overuse injuries in five Norwegian sports: Application of a new surveillance method. Scand J Med Sci Sports 2015;25:323-30.

2 Giroto N, Hespanhol Junior LC, Gomes MR, et al. Incidence and risk factors of injuries in Brazilian elite handball players: A prospective cohort study. Scand J Med Sci Sports 2017;27:195-202.

3 Bahr R, Reeser JC. Injuries among world-class professional beach volleyball players. The Fédération Internationale de Volleyball beach volleyball injury study. Am J Sports Med 2003;31:119-25.

4 Seminati E, Minetti AE. Overuse in volleyball training/practice: A review on shoulder and spine-related injuries. Eur J Sport Sci 2013;13:732-43.

5 Fahlström M, Yeap JS, Alfredson H, et al. Shoulder pain - a common problem in world-class badminton players. Scand J Med Sci Sports 2006;16:168-73.

6 Matsuura T, Suzue N, Iwame T, et al. Epidemiology of shoulder and elbow pain in youth baseball players. Phys Sportsmed 2016;44:97-100.

7 Ranson C, Gregory PL. Shoulder injury in professional cricketers. Phys Ther Sport 2008;9:34-9.

8 Møller M, Attermann J, Myklebust G, et al. Injury risk in Danish youth and senior elite handball using a new SMS text messages approach. Br J Sports Med 2012;46:531-7.

9 Verhagen EA, Van der Beek AJ, Bouter LM, et al. A one season prospective cohort study of volleyball injuries. Br J Sports Med 2004;38:477-81.

10 Clarsen B, Bahr R, Andersson SH, et al. Reduced glenohumeral rotation, external rotation weakness and scapular dyskinesis are risk factors for shoulder injuries among elite male handball players: a prospective cohort study. Br J Sports Med 2014;48:1327-33.

11 Myklebust G, Hasslan L, Bahr R, et al. High prevalence of shoulder pain among elite Norwegian female handball players. Scand J Med Sci Sports 2013;23:288-94.

12 van Mechelen W, Hlobil H, Kemper HC. Incidence, severity, aetiology and prevention of sports injuries. A review of concepts. Sports Med 1992;14:82-99.

13 Finch C. A new framework for research leading to sports injury prevention. J Sci Med Sport 2006;9:3-9.

14 Dick R, Lincoln AE, Agel J, et al. Descriptive epidemiology of collegiate women's lacrosse injuries: National Collegiate Athletic Association Injury Surveillance System, 1988-1989 through 2003-2004. J Athl Train 2007;42:262-9.

15 Dick R, Romani WA, Agel J, et al. Descriptive epidemiology of collegiate men's lacrosse injuries: National Collegiate Athletic Association Injury Surveillance System, 19881989 through 2003-2004. J Athl Train 2007;42:255-61.

16 Engebretsen L, Soligard T, Steffen K, et al. Sports injuries and illnesses during the London Summer Olympic Games 2012. Br J Sports Med 2013;47:407-14.

17 Junge A, Engebretsen L, Mountjoy ML, et al. Sports injuries during the Summer Olympic Games 2008. Am J Sports Med 2009;37:2165-72.

18 Hägglund M, Waldén $M$, Ekstrand J. Injuries among male and female elite football players. Scand J Med Sci Sports 2009;19:819-27.

19 Larruskain J, Lekue JA, Diaz N, et al. A comparison of injuries in elite male and female football players: A five-season prospective study. Scand J Med Sci Sports 2018;28.

20 Kibler WB, Wilkes T, Sciascia A. Mechanics and pathomechanics in the overhead athlete. Clin Sports Med 2013;32:637-51.

21 Manske R, Wilk KE, Davies G, et al. Glenohumeral motion deficits: friend or foe? Int J Sports Phys Ther 2013;8:537-53.

22 Chu SK, Jayabalan P, Kibler WB, et al. The kinetic chain revisited: new concepts on throwing mechanics and injury. Pm R 2016;8(Suppl):S69-77.

23 Fleisig GS, Barrentine SW, Escamilla RF, et al. Biomechanics of overhand throwing with implications for injuries. Sports Med 1996;21:421-37.

24 Vincent HK, Zdziarski LA, Vincent KR. Review of lacrosse-related musculoskeletal injuries in high school and collegiate players. Sports Health 2015;7:448-51.

25 Olivier B, Taljaard T, Burger E, et al. Which extrinsic and intrinsic factors are associated with non-contact injuries in adult cricket fast bowlers? Sports Med 2016;46:79-101.

26 Grantham WJ, lyengar JJ, Byram IR, et al. The curveball as a risk factor for injury: a systematic review. Sports Health 2015;7:19-26.

27 Webster MJ, Morris ME, Galna B. Shoulder pain in water polo: a systematic review of the literature. J Sci Med Sport 2009;12:3-11.

28 Challoumas D, Stavrou A, Dimitrakakis G. The volleyball athlete's shoulder: biomechanical adaptations and injury associations. Sports Biomech 2017;16:220-37.

29 Kilic O, Maas M, Verhagen E, et al. Incidence, aetiology and prevention of musculoskeletal injuries in volleyball: A systematic review of the literature. Eur J Sport Sci 2017;17:765-93.

30 Moher D, Liberati A, Tetzlaff J, et al. Preferred reporting items for systematic reviews and meta-analyses: the PRISMA statement. BMJ 2009;339:b2535.

31 van Tulder M, Furlan A, Bombardier C, et al. Updated method guidelines for systematic reviews in the cochrane collaboration back review group. Spine 2003;28:1290-9.

32 Reurink G, Goudswaard GJ, Tol JL, et al. Therapeutic interventions for acute hamstring injuries: a systematic review. Br J Sports Med 2012;46:103-9.

33 Green B, Pizzari T. Calf muscle strain injuries in sport: a systematic review of risk factors for injury. Br J Sports Med 2017;51:1189-94. 
34 Schut L, Wangensteen A, Maaskant J, et al. Can clinical evaluation predict return to sport after acute hamstring injuries? A systematic review. Sports Med 2017;47:1123-44.

35 Agel J, Palmieri-Smith RM, Dick R, et al. Descriptive epidemiology of collegiate women's volleyball injuries: National Collegiate Athletic Association Injury Surveillance System, 1988-1989 through 2003-2004. J Athl Train 2007;42:295-302.

36 Andersson SH, Bahr R, Clarsen B, et al. Preventing overuse shoulder injuries among throwing athletes: a cluster-randomised controlled trial in 660 elite handball players. Br J Sports Med 2017;51.

37 Bonza JE, Fields SK, Yard EE, et al. Shoulder injuries among United States high school athletes during the 2005-2006 and 2006-2007 school years. J Ath/ Train 2009:44:76-83.

38 Dick R, Sauers EL, Agel J, et al. Descriptive epidemiology of collegiate men's baseball injuries: National Collegiate Athletic Association Injury Surveillance System, 19881989 through 2003-2004. J Athl Train 2007;42:183-93.

39 Gardner EC, Chan WW, Sutton KM, et al. Shoulder Injuries in men's collegiate lacrosse, 2004-2009. Am J Sports Med 2016;44:2675-81.

40 Hinton RY, Lincoln AE, Almquist JL, et al. Epidemiology of lacrosse injuries in high school-aged girls and boys: a 3-year prospective study. Am J Sports Med 2005;33:1305-14.

41 Marshall SW, Hamstra-Wright KL, Dick R, et al. Descriptive epidemiology of collegiate women's softball injuries: National Collegiate Athletic Association Injury Surveillance System, 1988-1989 through 2003-2004. J Athl Train 2007:42:286-94.

42 Owens BD, Agel J, Mountcastle SB, et al. Incidence of glenohumeral instability in collegiate athletics. Am J Sports Med 2009;37:1750-4.

43 Reeser JC, Gregory A, Berg RL, et al. A comparison of women's collegiate and girls' high school volleyball injury data collected prospectively over a 4-year period. Sports Health 2015;7:504-10.

44 Robinson TW, Corlette J, Collins CL, et al. Shoulder injuries among US high school athletes, 2005/2006-2011/2012. Pediatrics 2014;133:272-9.

45 Wilk KE, Macrina LC, Fleisig GS, et al. Deficits in glenohumeral passive range of motion increase risk of shoulder injury in professional baseball pitchers: a prospective study. Am J Sports Med 2015;43:2379-85.

46 Hibberd EE, Kerr ZY, Roos KG, et al. Epidemiology of acromioclavicular joint sprains in 25 National Collegiate Athletic Association sports: 2009-2010 to 2014-2015 academic years. Am J Sports Med 2016;44:2667-74.

47 Noonan TJ, Thigpen CA, Bailey LB, et al. Humeral torsion as a risk factor for shoulder and elbow injury in professional baseball pitchers. Am J Sports Med 2016;44:2214-9.

48 Sallis RE, Jones K, Sunshine $\mathrm{S}$, et al. Comparing sports injuries in men and women. Int J Sports Med 2001;22:420-3.

49 Matsuura T, Iwame T, Suzue N, et al. Risk factors for shoulder and elbow pain in youth baseball players. Phys Sportsmed 2017;45:1-5.

50 Møller M, Nielsen RO, Attermann J, et al. Handball load and shoulder injury rate: a 31-week cohort study of 679 elite youth handball players. Br J Sports Med 2017;51:231-7.

51 Gregory PL, Batt ME, Wallace WA. Comparing injuries of spin bowling with fast bowling in young cricketers. Clin J Sport Med 2002;12:107-12.

52 Forthomme B, Wieczorek V, Frisch A, et al. Shoulder pain among high-level volleyball players and preseason features. Med Sci Sports Exerc 2013;45:1852-60.

53 Bere T, Kruczynski J, Veintimilla N, et al. Injury risk is low among world-class volleyball players: 4-year data from the FIVB Injury Surveillance System. Br J Sports Med 2015;49:1132-7.

54 Polster JM, Bullen J, Obuchowski NA, et al. Relationship between humeral torsion and injury in professional baseball pitchers. Am J Sports Med 2013;41:2015-21.

55 Shanley E, Kissenberth MJ, Thigpen CA, et al. Preseason shoulder range of motion screening as a predictor of injury among youth and adolescent baseball pitchers. J Shoulder Elbow Surg 2015;24:1005-13.

56 Shanley E, Rauh MJ, Michener LA, et al. Incidence of injuries in high school softball and baseball players. J Ath/ Train 2011;46:648-54.
57 Smith MV, Davis R, Brophy RH, et al. Prospective player-reported injuries in female youth fast-pitch softball players. Sports Health 2015;7:497-503.

58 Yung PS, Chan RH, Wong FC, et al. Epidemiology of injuries in Hong Kong elite badminton athletes. Res Sports Med 2007:15:133-46.

59 Wang HK, Cochrane T. A descriptive epidemiological study of shoulder injury in top level English male volleyball players. Int J Sports Med 2001;22:159-63.

60 Byram IR, Bushnell BD, Dugger K, et al. Preseason shoulder strength measurements in professional baseball pitchers: identifying players at risk for injury. Am J Sports Med 2010;38:1375-82.

61 Lyman S, Fleisig GS, Andrews JR, et al. Effect of pitch type, pitch count, and pitching mechanics on risk of elbow and shoulder pain in youth baseball pitchers. Am J Sports Med 2002;30:463-8.

62 Lyman S, Fleisig GS, Waterbor JW, et al. Longitudinal study of elbow and shoulder pain in youth baseball pitchers. Med Sci Sports Exerc 2001;33:1803-10.

63 Polster JM, Lynch TS, Bullen JA, et al. Throwing-related injuries of the subscapularis in professional baseball players. Skeletal Radiol 2016;45:41-7.

64 Struyf F, Nijs J, Meeus M, et al. Does scapular positioning predict shoulder pain in recreational overhead athletes? Int J Sports Med 2014;35:75-82.

65 Wright RW, Steger-May K, Klein SE. Radiographic findings in the shoulder and elbow of Major League Baseball pitchers. Am J Sports Med 2007;35:1839-43.

66 Seil R, Rupp S, Tempelhof S, et al. Sports injuries in team handball. A one-year prospective study of sixteen men's senior teams of a superior nonprofessional level. Am J Sports Med 1998;26:681-7.

67 Sell K, Hainline B, Yorio M, et al. Injury trend analysis from the US Open Tennis Championships between 1994 and 2009. Br J Sports Med 2014;48:546-51.

68 Wilk KE, Macrina LC, Fleisig GS, et al. Correlation of glenohumeral internal rotation deficit and total rotational motion to shoulder injuries in professional baseball pitchers. Am J Sports Med 2011;39:329-35.

69 Dick RW. Is there a gender difference in concussion incidence and outcomes? Br J Sports Med 2009;43(Suppl_1):i46-i50.

70 Waldén M, Hägglund M, Ekstrand J. The epidemiology of groin injury in senior football: a systematic review of prospective studies. Br J Sports Med 2015;49:792-7.

71 Waldén $M$, Hägglund $M$, Werner J, et al. The epidemiology of anterior cruciate ligament injury in football (soccer): a review of the literature from a gender-related perspective. Knee Surg Sports Traumatol Arthrosc 2011;19:3-10.

72 Waldén M, Hägglund M, Ekstrand J. Injuries in Swedish elite football-a prospective study on injury definitions, risk for injury and injury pattern during 2001. Scand J Med Sci Sports 2005;15:118-25.

73 Williams S, Trewartha G, Kemp S, et al. A meta-analysis of injuries in senior men's professional Rugby Union. Sports Med 2013;43:1043-55.

74 Bahr R. No injuries, but plenty of pain? On the methodology for recording overuse symptoms in sports. Br J Sports Med 2009;43:966-72.

75 Nielsen RØ, Malisoux L, Møller M, et al. Shedding light on the etiology of sports injuries: a look behind the scenes of time-to-event analyses. J Orthop Sports Phys Ther 2016:46:300-11

76 Wasserstein R, Lazar N. The ASA's Statement on p-Values: Context, Process, and Purpose. The American statistician 2016;50:127-32.

77 Ardern CL, Winters M. Synthesising 'best evidence'in systematic reviews when randomised controlled trials are absent: three tips for authors to add value for clinician readers. Br J Sports Med 2017. doi:10.1136/bjsports-2017-097881. [EPub ahead of print 22 Jul 2017].

78 Sackett DL, Rosenberg WM, Gray JA, et al. Evidence based medicine: what it is and what it isn't. BMJ 1996;312:71-2.

79 Bahr R. Why screening tests to predict injury do not work-and probably never will...: a critical review. Br J Sports Med 2016;50:776-80.

80 Ardern CL, Glasgow P, Schneiders A, et al. 2016 Consensus statement on return to sport from the First World Congress in Sports Physical Therapy, Bern. Br J Sports Med 2016;50:853-64

81 Clarsen B, Moseby Berge H. Screening is dead. Long live screening!. Br J Sports Med 2016;50:769. 